\title{
BENEFITS ASSESSMENT OF TRAINING ON SUPPLY CHAIN MANAGEMENT: THE CASE OF A GLOBAL CHEMICAL CORPORATION
}

\author{
Claudemir Leif Tramarico \\ Sao Paulo State University \\ Guaratingueta, BRAZIL \\ E-mail: claudemir.leif@terra.com.br \\ Fernando Augusto Silva Marins \\ Sao Paulo State University \\ Guaratingueta, BRAZIL \\ E-mail: fmarins@feg.unesp.br \\ Ligia Maria Soto Urbina \\ Technological Institute of Aeronautics \\ Sao Jose dos Campos, BRAZIL \\ E-mail: ligia@,ita.br \\ Valerio Antonio Pamplona Salomon \\ Sao Paulo State University \\ Guaratingueta, BRAZIL \\ E-mail: salomon@feg.unesp.br
}

\begin{abstract}
Modern organizations rely upon their core competencies to support their competitive advantages. In that context, organizational functions should contribute for strengthening company's core competencies. Nowadays, supply chain management has to be developed in order to achieve competitiveness in global markets. In such a context, global organizations have invested to improve supply chain management capabilities. It is expected that such efforts should have positive impacts on organizational and individual competencies as well as on the related core competencies. However, it must be pointed out that these benefits are not easily accounted. Therefore, this paper proposes the assessment of benefits from a training program developed in a real company, to support its supply chain management. With this aim, this paper presents a set of relevant criteria, which can capture, on one side, the training impacts on the related core competencies, and on the other side, the expected benefits on organizational and individual competencies. Analytic Hierarchy Process is applied, surveying the trained employees and their managers.
\end{abstract}

Keywords: Analytic Hierarchy Process, Supply Chain Management, Training. 
ISAHP Article: Tramarico et al. / assessment of benefits from supply chain management training: case of a global chemical corporation

\section{Introduction}

Supply chain management (SCM) is a critical factor in the current global scenario. Most organizations have invested to develop SCM capabilities. However, benefits from training on SCM are not easily accounted. Usually, evaluation of training on SCM is often based on the participant's reaction, but the benefits detected do not emerge from any structured model. An important set of individual and organizational benefits that arise from SCM training programs is suggested by APICS - the Association for Operations Management (CPIM Brochure, 2011). However, APICS does not provide a benefits assessment that allows to measure the impact of a particular training program on, both, the SCM competencies, and on other related organizational competencies, thus providing benefits for the organization as a whole. In that context this paper contributes proposing an evaluation model for a specific program training on SCM of a global chemical company, which allows to capture its impact on organizational and individual competencies, as well as on the core competencies.

The research methods adopted in this paper are mathematical modelling and survey. Section 2 introduces the Theory Background, mainly with concepts on SCM training and multi-criteria assessment. In Section 3 the training assessment is presented. The paper ends with Conclusions and the Key References.

\section{Theory Background}

\subsection{Supply chain management}

APICS defines SCM as the "design, planning, execution, control, and monitoring of supply chain activities with the objective of creating net value, building a competitive infrastructure, leveraging worldwide logistics, synchronizing supply with demand and measuring performance globally" (Blackstone, 2013).

Training in SCM has been growing as one of the most relevant bases to become Certified in Production and Inventory Management (CPIM) from the APICS. The goal of APICS is to build and validate the knowledge management supply chain and the operations management, providing certification programs for the community, members and customers. Certification as a strategic advantage is quite necessary in the present globalized world (Lummus, 2007). CPIM contributes to the field of terminology concepts and strategies related to SCM: Demand Management, Master Production Scheduling, Materials Planning, Capacity Management, Sales and Operations Planning, Production Environments and Process, Purchasing, Physical Distribution, Performance Measures, Supplier Relationships, Lean and Just-In-Time, Quality Systems and Continuous Improvement (Blackstone, 2013). 
ISAHP Article: Tramarico et al. / assessment of benefits from supply chain management training: case of a global chemical corporation

\subsection{Training assessment and multi-criteria assessment method}

APICS suggests that SCM training could be evaluated using two sets of individual and organizational benefits, related to adoption of best practices on SCM resulting of the knowledge and competencies improvement of SCM functions, technologies, people, and the related collaborative network (CPIM Brochure, 2011).

However, it is argued here that training in SCM could also have a pervasive impact on core competencies.

Thus, a comprehensive training assessment model should take into account the benefits related to the improvement of core, organizational and individual competencies. Prahalad and Hamel (1990,p.82) defined core competencies as "the collective learning in the organization, especially how to coordinate diverse production skills and integrate multiple streams of technologies". These competencies do differentiate the company from its competitors creating a competitive differentiation that enchants clients, and propitiates sustainable advantages. Organizational competencies which are specific competencies by business area such as Design, Marketing, Sales, Production and Logistics. Some of them are core competencies of the organization, because they are reasons for the company's survival, while others serve as supporters (Fleury and Fleury, 2001). Individual competencies are the skills and capabilities in every person which reflect both the intrinsic and acquired knowledge and personal characteristics (Fleury and Fleury, 2004)

Training in SCM can be assessed using qualitative criteria to quantitatively assess various process of SCM. The Analytic Hierarchy Process (AHP) application in the solution of these problem uses hierarchy models. Hierarchies facilitate the understanding of complex problems (Saaty, 2010).

There is also possibility of using ratings, also know as "absolute measures" in AHP application, i.e. each alternative is compared with many other alternatives, while ratings compare each alternative with an ideal one (Saaty, 2006). Table 1 presents the degrees of quality set for training assessment.

Table 1

Five-level degrees of quality

\begin{tabular}{lll}
\hline Level & Degree of quality & Priority \\
\hline 1 & Poor & 0 \\
2 & Between Poor and Fair & 0.20 \\
3 & Fair & 0.34 \\
4 & Between Fair and Good & 0.59 \\
5 & Good & 1 \\
\hline
\end{tabular}

Priorities presented in Table 1 were obtained normalizing components of the right eigenvector, $\mathbf{w}$, the comparison matrix, $\mathbf{A}$, presented in Table 2 . As for Poor we have zero priority, this degree was not compared. The inconsistency index, $(\lambda-n) /(n-1)$, for the comparison matrix presented in Table 2 is around 0.01 . 
ISAHP Article: Tramarico et al. / assessment of benefits from supply chain management training: case of a global chemical corporation

Table 2

Pairwise comparisons of degrees of quality

\begin{tabular}{lllll}
\hline & G & BFG & F & BPF \\
\hline Good (G) & 1 & 2 & 3 & 4 \\
Between Fair and Good (BFG) & $1 / 2$ & 1 & 2 & 3 \\
Fair (F) & $1 / 3$ & $1 / 2$ & 1 & 2 \\
Between Poor and Fair (BPF) & $1 / 4$ & $1 / 3$ & $1 / 2$ & 1 \\
\hline
\end{tabular}

\section{Evaluation of SCM training}

The research presented in this paper was conducted in a global chemical company. Employers and their managers from chemical plants located in the State of Sao Paulo, Brazil, were surveyed. The researched company has around 1,000 employees (including managers) in Brazil, and it is one of the top 10 companies in the chemical and petrochemical branches. The company's core competencies were defined as: Drive Innovation, Collaborate for Achievement, Drive Sustainable Solutions, Act with Entrepreneurial Drive, and Demonstrate Customer Focus.

A training program was implemented one year ago to prepare to APICS CPIM with five modules of 32 hours each. More than 100 employees have participated in the training program. Frequently asked questions regarding the SCM training gains are: "Does the SCM training program deliver individual benefits?", "Does the training program deliver organizational benefits?", and "Does the training program contribute for the strengthening of the company's core competencies?"

Figure 1 presents the hierarchy model applied in the assessment of SCM training. Company's core competencies are the criteria, in the middle level. In the bottom level there are the individual and organizational benefits from the SCM.

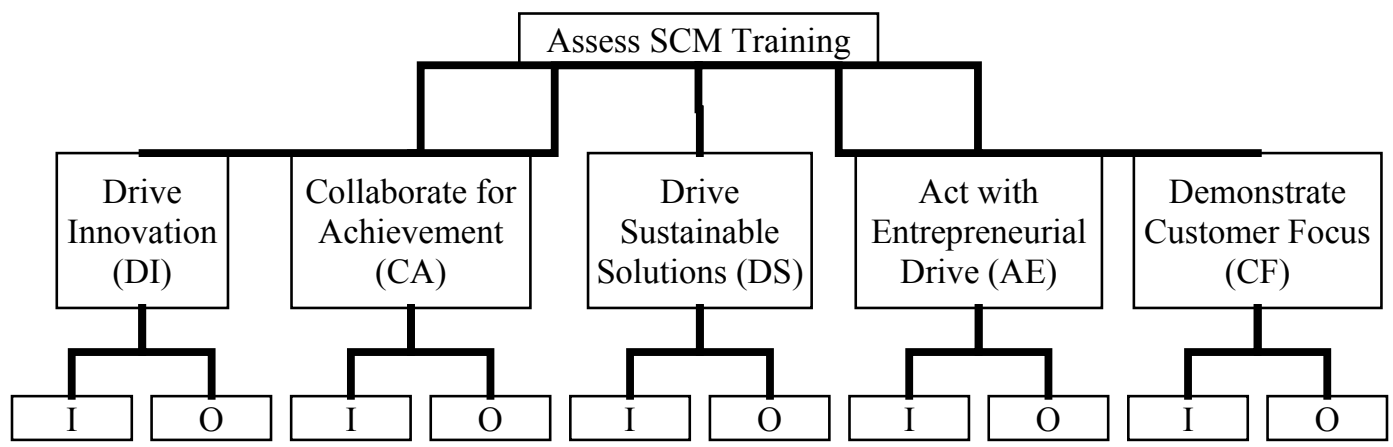

Figure 1 Hierarchy model for training assessment. (I: individual benefits, O: Organizational benefits)

174 company's employers and managers were surveyed. They filled up forms evaluating the training benefit according the degree of quality perceived for them to each one of the company's core competence. Table 3 presents the survey's results. For instance, 26 
ISAHP Article: Tramarico et al. / assessment of benefits from supply chain management training: case of a global chemical corporation

employee or managers judged that SCM training was "good" to benefit Drive Innovation (DI).

Table 3

Assessment from employees and managers

\begin{tabular}{llllll}
\hline Degree of quality (Priority) & DI & CA & DS & AE & CF \\
\hline Good (1) & 26 & 30 & 32 & 44 & 56 \\
Between Fair and Good (0.59) & 81 & 65 & 63 & 73 & 69 \\
Fair (0.34) & 51 & 56 & 53 & 36 & 41 \\
Between Poor and Fair (0.20) & 15 & 21 & 22 & 16 & 5 \\
Poor (0) & 1 & 2 & 4 & 5 & 3 \\
\hline
\end{tabular}

The aggregate priority for Drive Innovation was around 0.54, indicating that SCM training benefits to this core competence is close to Good. For Collaborate for Achievement (CA), and Drive Sustainable Solutions (DS), the result was not qualitative different being around 0.53. Act with Entrepreneurial Drive had an aggregated priority equal to 0.59 , and Demonstrate Customer Focus had the highest priority of 0.64 .

\section{Conclusions}

The main result of the analysis reveals that SCM training is really perceived as beneficial, in individual or organizational terms, to the organization. Then, the company should be confident on the SCM training program to improve and strengthening its core competencies.

The model presented in Section 3 can be improved prioritizing core competencies one against another. A new approach on Benefits, Opportunities, Costs and Risks (BOCR) is suggested as future research.

\section{Key References}

Blackstone, J.H.Jr. (Ed.) (2013). APICS Dictionary. 14 ${ }^{\text {th }}$ Edition. Chicago: APICS.

Fleury, M.T.L. \& Fleury, A. (2001). Construindo o conceito de competencia. Rev. Adm. Contemp., 5, 183-196.

Fleury, M.T.L. \& Fleury, A. (2004). Alinhando estratégia e competências. Revista de Administração de Empresas, 44(1), 44-57.

Lummus, R.R. (2007). The role of APICS in professionalizing operations management. Journal of Operations Management, 25, 336-345.

Prahalad, C. and Hamel, G. (1990). The Core competence of the corporation. Harvard Business Review, 68, 79-91.

Saaty, T.L. (2006). Rank from comparisons and from ratings in the analytic hierarchy/network processes. European Journal of Operational Research, 168, 557-570.

Saaty, T.L. (2010). Principia Mathematica Decernendi: Mathematical principles of decision-making. Pittsburgh: RWS.

International Symposium on the

Analytic Hierarchy Process 